IJ§ER

ISSN: 2149-5939
International Journal of Social Sciences and Education Research

Online, http://dergipark.gov.tr/ijsser

Volume: 4(1), 2018

\title{
Personal responsibility and interpersonal communication in a project-based learning environment
}

\author{
Tanju Deveci ${ }^{1} \quad$ Nader Ayish ${ }^{2}$ \\ Received Date: 31 / 07 / 2017 \\ Accepted Date: 25 / $10 / 2017$
}

\begin{abstract}
A common refrain among many educators is that freshman university students, especially those involved with project-based learning, lack empathy and are mainly concerned with their own well-being. Unfortunately, it is often assumed that students, once put on teams, will acquire, through personal responsibility, the essential interpersonal skills necessary for success. To determine if this is the case within the context of an engineering university in the UAE, 143 freshman students' responsibility and interpersonal communication propensities in two project-based courses were analysed. Data were collected using two questionnaires. Students' scores were analysed according to gender and the courses they attended as well as the relationship between their responsibility and interpersonal communication. Results indicate that both the students' responsibility and interpersonal communication scores were at a moderate level, while students' responsibility scores in the second level course were higher. In addition, female students' interpersonal communication scores were more varied than male students'. Results are discussed and recommendations are made as to how to increase students' responsibility behaviours in courses that require the effective use of interpersonal communication skills.
\end{abstract}

Keywords: Responsibility, Interpersonal Communication, Project-Based Learning, Team-Based Learning, Gender, Freshman

\section{Introduction}

The transition from high school to university can be challenging. As freshman entering a new learning environment, many students are confronted by new-found freedoms that often lead to, not only increased independence and decision making, but also increased personal responsibility. This increased personal responsibility, coupled with the challenges inherent in interpersonal communication, can impact a student's learning as well as that of his or her peers.

Personal responsibility, defined as "people [s' skill of] taking individual accountability for their decisions and actions, together with the outcomes they create and their impacts on others" (Linley \& Maltby, 2009, p. 685) is a key factor affecting learning orientations, and it impacts the degree to which students act as active agents of their own learning. In contexts where students team up with peers to work on projects and perform other collaborative tasks, they also directly impact their peers' learning, and the academic and personal well-being of everyone involved.

The impetus for this research comes from the observation that many of today's youth possess very low levels of empathy and are, instead, more concerned about their individual well-being (Konrath, O'Brien \& Hsing, 2011). It is argued that such self-absorption during the adolescent years is caused, in part, by periods of turbulence when individuals need to acquire new skills and

\footnotetext{
${ }^{1}$ Assistant Professor, Khalifa University of Science and Technology, Abu Dhabi, UAE, tanjudeveci@yahoo.com

${ }^{2}$ Assistant Professor, Khalifa University of Science and Technology, Abu Dhabi, UAE, nayish1@yahoo.com
} 
Deveci, T., Ayish, N. (2018). Personal responsibility and interpersonal communication in a project-based learning environment. International Journal of Social Sciences and Education Research, 4(1), 1-17.

competencies (Uche, 2012). The transition from high school to university often compounds the consequences of such turbulence. The issue is often exacerbated when university courses require students to complete assignments in teams. Students' limited personal responsibility may influence empathy skills reducing harmony in student teams. In addition, there appears to be a lack of interest in students' personal responsibility levels in courses where instruction is heavily based on team work. The lack of research in this area is apparent in the UAE context.

This is particularly important because a lack of personal responsibility can negatively impact not only an individual's academic success, but that of their team members. The effects can also be felt beyond university by negatively affecting students' overall well-being. Therefore, identifying student aptitude for responsibility, and understanding how it impacts their interpersonal communication skills relative to teaming can offer insight into a rather complex relationship.

\section{Literature}

\subsection{Interpersonal communication and personal responsibility}

Defined as "the process of message transaction between people to create and sustain shared meaning" (West \& Turner, 2009, p. 10), interpersonal communication is a complex concept. This is partly because individuals' perceptions of self, others and relationships impact on the nature of communication (LaVoi, 2007). It is also due to the fact that the word 'communication' has many meanings and interpretations and is complicated by such factors as the number of people engaged in communication or where communication takes place. Some suggest that interpersonal communication is "a distinct type of interaction between people," and the definition of interpersonal communication should be based on "what happens between people, [rather than] where they are or how many are present" (Wood, 2013, p. 20).

According to Lane (2016), successful interpersonal communication depends on three main factors that function together. The first one is the individual's motivation to communicate. One's level of confidence and interest in others involved in communication determines how much they like to engage in the communication. If interaction is perceived as rewarding, for example, the desire to communicate will increase. The second factor that affects the effectiveness of interpersonal communication is the knowledge about oneself, others involved in the conversation, the topic, the situation, and the communication process itself. The third one, on the other hand, concerns skill, which refers to "the actual performance of action sequences" (p. 10) where individuals put their knowledge into practice.

Responsibility plays a key role in achieving success in interpersonal communication. Arnett, Fritz and Bell (2009) use the term 'interpersonal responsibility' to draw attention to the importance of responsibility. In their view, "interpersonal responsibility begins with each person's commitment to [actively caring] for the interpersonal relationship, owned by neither and nurtured with or without the support of the Other" (p. 121). This requires an ethical orientation to building relationships with others in which each party commits to binding the relationship together. Individuals need to use interpersonal skills to nourish the relationship they are in, whatever the nature of it may be. This underscores the role of responsibility included in Linley and Maltby's definition (2009) above in that individuals are held responsible for considering the impact of their decisions and actions on others, which in turn supports interpersonal relationships. This points to a reciprocal relationship indicating that "responsibility for good communication is shared [and] 
Deveci, T., Ayish, N. (2018). Personal responsibility and interpersonal communication in a project-based learning environment. International Journal of Social Sciences and Education Research, 4(1), 1-17.

one person cannot make communication successful, nor is one person totally responsible for problems" (Wood, 2016, p. 22). However, individuals' raised awareness of their own role in determining the extent to which a relationship is successful is at the heart of effective interpersonal communication. Individuals' willingness to assume responsibility therefore engages them in intrapersonal communication helping them become aware of their feelings and thoughts as well as how others may think and feel. Control over one's own feelings and thoughts and owning up to them instead of blaming others for problems improves interpersonal communication. This lets others know what one is experiencing, which puts the individual in a better position to respond (Pfeiffer, 1998). As a result, the quality of the interpersonal communication increases.

\subsection{Responsibility and interpersonal communication in team-based learning}

There are many venues in which we engage in intensive interpersonal communication, including when teaming. Some of the earliest signs of team work can be traced to when humans first started to hunt for food. It has since become even more important as life has become more complicated (Hills, 2001). However, considering some of the complexities of interpersonal communication discussed above, it may not be easy for a team to be successful. Two central defining characteristics of a team are that there is "a high level of individual commitment to the welfare of the group, [and] a high level of trust among the members" (Fink, 2002, p. 11). For a team to be successful, therefore, individual members need to exhibit a high level of effort, which requires individual responsibility in various forms.

Considering Vygotsky's well-established argument (1962) that our interaction with others in our social environments impacts the learning process, the role of teams in educational contexts becomes more noticeable. Team-based learning (TBL) "stimulates students to more accurately perceive what capacities lie within themselves and their team mates" (Sweet, 2008, p. 15). This encourages them to engage in collaborative learning which requires individual responsibility for covering basic content outside the classroom and shifting the focus to students working together in the classroom (Fines, 2012). Students becoming active agents of the learning process makes them responsible for their initial exposure to the course content and prepares them for in-class teamwork (Michaelson \& Sweet, 2008). This is based on the belief that "Students are entirely capable of learning material from a good textbook if they are motivated to do so. The structure of TBL ensures that students are so motivated because their grade depends upon both their individual and team performance" (Dana, 2007, p. 14). For this to succeed, however, individual students need to assume continuous responsibility for learning. This also gives them the responsibility for helping their peers' learning since they need to share what they have learned outside of the classroom with their team mates. In fact, "the willingness of each member of the team to have a high regard for the learning needs of others" (Hills, 2001, p. 7), is the hallmark of TBL. This entails that students become fully aware of their own as well as their peers' personality types, motivations, desires, and learning needs. This requires students to acquire interpersonal communication skills, which can be developed and enhanced through an increased awareness of personal responsibilities. It is suggested, therefore, that the success of team-based learning can stem from the awareness of each team member's individual roles and responsibilities and the kind of relationship that forms as a result (Samad, Rashid, Rahman \& Hussein, 2014).

\subsection{Interpersonal communication and responsibility in project-based learning}

It is well-established that job specific knowledge and skills alone are inadequate in the workplace. Individuals also need soft-skills, which include the ability to effectively communicate 
Deveci, T., Ayish, N. (2018). Personal responsibility and interpersonal communication in a project-based learning environment. International Journal of Social Sciences and Education Research, 4(1), 1-17.

orally and in writing, to apply knowledge and skills to real-life world settings as well as criticalthinking and analytical-reasoning skills (Larmer, Mergendoller \& Boss, 2015). Education institutions mindful of these provide students with opportunities to acquire and practice such skills. Defined as "a teaching method in which students gain knowledge and skills by working for an extended period of time to investigate and respond to an engaging and complex question, problem, or challenge" (Buck Institute for Education, n.d.), Project-based Learning (PBL) seems to create the ideal environment for this. This approach to teaching emphasizes the place of experiential learning in improving students' problem-solving and higher-order thinking skills (Boss \& Krauss, 2014). Evidence shows that the cognitive skills acquired in a PBL environment increase students' ability to apply knowledge in novel, problem-solving contexts (Kannan, Mahajan \& Rajkumar, 2016).

PBL shifts the teacher's role from the knowledge expert to the facilitator of the learning process. Small teams of students interact with each other to perform collaborative tasks to carry out projects (Ozel, 2013). For projects to succeed, students need to exhibit what Atkinson (2001) calls 'people skill[s]' involving 'tolerance, willingness to help, communication, negotiation, acceptance, [and] persuasion" (p. 3). These point to the role of interpersonal communication to achieve project goals. There is empirical evidence that students' engagement in PBL encourages them to become perceptive and sensitive to the needs of others (Musa, Mufti, Latiff \& Amin, 2012), assume responsibility for their own and peers' learning (Iwamoto, Hargis \& Vuong, 2016), and effectively fulfil a position in (engineering) teams (Chartier \& Gibson, 2007). It has also been shown that PBL experience helps students to recognize their active role in the team and develop interpersonal skills (Alves, Mesquita, Moreira \& Fernandes, 2012).

\subsection{Role of gender in interpersonal communication}

Many people believe that males and females communicate differently. Popular culture has contributed to this perception through best-selling books, such as "Men are from Earth, Women are from Venus" (Gray, 1992) and "You Just Don't Understand: Women and Men in Conversation" (Tannen, 2007). While some studies suggest that the perceived differences are more nuanced, less conclusive, and heavily contextual (Ingram \& Parker, 2002; Jones, Ruff \& Paretti, 2013), other studies have shown that gender can play an important role in the way males and females communicate interpersonally. Wolfe and Powell (2009), for example, found that female engineering students used more conciliatory language when communicating with male team members in order to avoid conflict or to achieve particular objectives. Such speech acts, however, were generally perceived by male teammates as a sign of weakness and often led to some female students to doubt their abilities, withdraw from active team participation, and second-guess their decision to pursue an engineering degree. These types of encounters likely contribute to the disproportionately high level of female students changing engineering majors or dropping out of university all together. Kobalgrum and Grum (2015) also found that female students are generally more satisfied with their psychological needs than male students. They suggest that the type of interpersonal relationships and communication styles that males and females form early in life directly shapes how each gender responds to and interacts with the other.

Amelink and Creamer (2010) also found that female and male students often interact differently on teams, approach problem-solving differently, and have different kinds of interactions with faculty. Such interpersonal communication differences often lead to negative consequences for female students. In particular, "gender biased behavior and male dominated cultural norms 
Deveci, T., Ayish, N. (2018). Personal responsibility and interpersonal communication in a project-based learning environment. International Journal of Social Sciences and Education Research, 4(1), 1-17.

may negatively impact the undergraduate experience of females in engineering degree programs" (p. 89). The importance of positive student-faculty interactions and peer respect were noted as key factors that may help ameliorate the negative experiences some female students encounter during their undergraduate studies.

\subsection{Impact of gender on responsibility}

Just as many people believe that males and females communicate differently, so too is there a general perception that differences exist in terms of gender and responsibility. Our experience teaching a range of courses in a number of universities in several countries suggests that female students tend to be more responsible than male students. However, it is important to note that the concept of being responsible is culturally bound and highly contextual (Adamson \& Sert, 2012; Littlewood, 1999; Pennycook, 1997). In addition, gender differences have not been extensively studied. This is particularly true in our regional context.

While research generally supports our experience, some studies also reveal that there are often no statistical differences between females' and males' responsibility behaviours (Edgar, 2015; Severiens \& Dam, 2012). Nonetheless, as Cesur \& Ertas (2013) found in a study examining preparatory students' English language learning, females were more responsible than males in planning what to study, adjusting how they learn, and correcting errors in their assignments. Üstünlüoğlu (2009) also reports that females demonstrated more responsibility in terms of participation related to autonomous language learning. That gender, at times, impacts responsibility points to the complexity of the relationships that exists between these two variables and the need to better understand this relationship across domains.

\section{Researchers' context and rationale for the study}

This research was undertaken at the Petroleum Institute (PI), Khalifa University of Science and Technology, Abu Dhabi, United Arab Emirates, which offers undergraduate and graduate degrees in various engineering disciplines. The PI is accredited by ABET Engineering Accreditation Commission. ABET-accredited programs are required to prepare graduates to meet certain educational objectives. These include the ability to communicate effectively and function on multidisciplinary teams (ABET, 2013). In order for the PI to fully address these objectives, it is important to identify students' strengths and areas in need of development. Only then can the necessary instructional interventions be planned. Assuming that students possess these skills may lead programs to build their instruction on weak foundations, which could impact students' success at and beyond university. This current study is an attempt to shed light on student readiness for team-work that is greatly influenced by their communication skills and aptitude for assuming responsibly.

Part of the effort to support students in developing these skills at the PI comes from the English and Communication Department which aims to provide students with some of the soft skills they need to be successful engineers. These include a variety of team-work skills. The department strives to assist students in acquiring these skills in two communication courses (COMM101 \& COMM151) through project-based learning (PBL). Students are required to engage in significant interpersonal communication while carrying out team assignments. However, it is not uncommon to hear complaints by students about some team members not working appropriately in teams. Some common refrains are that certain team members are not responsible, do not take their roles 
Deveci, T., Ayish, N. (2018). Personal responsibility and interpersonal communication in a project-based learning environment. International Journal of Social Sciences and Education Research, 4(1), 1-17.

seriously, and contribute little to the team's project. Two typical reasons given for these behaviours are a lack of self-efficacy and language proficiency. This often leads to groupthink and overdependence on more capable students on the team. It is also noted that time is often not used efficiently in team meetings and resources are wasted.

These observations by the researchers of this paper, along with those of other faculty and students, point to the significant role responsibility and interpersonal communication skills play in ensuring the success of these two PBL-based communication courses. However, it may be the case that students' willingness to take responsibility for their own and peers' learning as well as the skill level and interest in interpersonal communication are taken for granted. These assumptions should be reconsidered, given that many students newly admitted to our university may have had no or limited opportunity to work in teams in high school. This is particularly important because, as Thabet (2008) found, rote-learning and teacher-centered instruction is prevalent in public schools in the region. Therefore, it is not surprising that many students lack aptitude for assuming responsibility for learning and effective interpersonal communication skills.

Another important reason for this study comes from the lack of studies conducted into the correlation between responsibility and interpersonal communication skills in learning environments heavily based on team work. Although the role responsibility plays in achieving success in our interpersonal relationships seems self-evident, there is a dearth of studies exploring the correlation between the two factors. This study aims to fill this gap.

In addition, while gender has been extensively researched in the education field, little research has been conducted in single-sex educational contexts. This limits our understanding of student characteristics and needs in segregated campuses. The PI has two gender-segregated campuses. Identifying PI male and female students' responsibility and communication skills might help meet their needs more effectively. This is particularly important given that the UAE government has issued a recent decree to merge the PI with two other universities in the region to form a new university named 'Khalifa University of Science and Technology' (KUST). This requires the PI to adopt a coed-sex education policy. Although the existing students will be given a choice, new students will be admitted to KUST which adopts coed-sex education. It is hoped that the results of the current study on the PI students' characteristics may help education planners during their transition to a coed-sex education system.

\section{Research questions}

Given the importance of responsibility and interpersonal communication skills on student success, this research aims to answer the following questions:

1- What are students' responsibility levels? Does it change according to gender and courses attended?

2- What are their interpersonal communication levels? Does it change according to gender and course attended?

3- What kind of relationship exists between responsibility and interpersonal communication? Does it change according to gender and course? 
Deveci, T., Ayish, N. (2018). Personal responsibility and interpersonal communication in a project-based learning environment. International Journal of Social Sciences and Education Research, 4(1), 1-17.

\section{Methodology}

\subsection{Participants}

A total of 143 freshman students participated in this study. Seventy-eight (55\%) were COMM101 students, while 65 (45\%) were COMM151 students. Twenty-four (17\%) students were male and 119 ( 83\%) were female. Their ages ranged between 17 and 22, with a mean age of 19 .

\subsection{Data-gathering Instruments}

\subsubsection{The Personal Responsibility Questionnaire (PRQ)}

This questionnaire, developed by Mergler (2007), comprises 30 items that measure two factors that contribute to personal responbility: Self-control of emotions and thoughts and selfcontrol of behaviour. Internal consistency for the former was found to be 0.87 , and for the latter it was computed to be 0.79 . In this current study, internal consistency for the first factor was found to be 0.78 , while it was 0.71 for the second factor.

A four-point Likert-scale ( $1=$ strongly disagree, $4=$ strongly agree) is used for the instrument with positively and negatively worded items. Participants were asked to choose the responses that fit with them on most occasions. An example of a positive statement is, "When I experience a problem, I actively seek to resolve it." On the other hand, an example of a negatively worded statement is, "I sometimes become 'wild and crazy' and do things other people may not like." The highest score possible on the questionnaire is 120 , while the lowest is 30 . The higher one's score, the higher level of personal responsibility (s)he has.

\subsubsection{The Communication Skills Scale (CSC)}

The English version of the CSC, originally developed in Turkish by Korkut (1996), was used to collect data on the participants' interpersonal communication skills. The principle author (a native speaker of Turkish) of this current study first translated the scale from its original language into English. It was then validated by two native speakers' of English. The translated version was piloted with a group of ten students before it was adminstered to the whole population.

There are a total of 25 statements included in the scale. Sample statements include, "I can look at thing from different perspectives," and "I don't offer peple advice unless they ask for it." Participants are asked to indicate how often the statements applied to them on a Likert-scale of 5 $-1(5=$ Always and $1=$ Never $)$. The highest total score possible is 125 . The average score is 62.5 , while the minimum is 25 . Higher scores indicate better interpersonal communication skills. Korkut found the internal consistency of the scale to be 0.76 . Similarly, in this study it was found to be 0.79 .

\subsection{Analyses}

Data collected were analysed using descriptive statistics such as frequencies, mean, minimum and maximum. Student's t-test was used to analyze the significance of responsibility and communication skills by gender and course. In addition, the Pearson product-moment correlation coefficient ( $r$ ) was used to measure the strength of association between the personality scores and communication scores of the participants. A p-value of 0.05 was considered statistically significant for both statistical analyses. 
Deveci, T., Ayish, N. (2018). Personal responsibility and interpersonal communication in a project-based learning environment. International Journal of Social Sciences and Education Research, 4(1), 1-17.

\section{Results}

The first research question was related to the students' responsibility levels. Table 1 below displays the results of data analysis, and compares the two courses.

Table 1. Responsibility Scores

\begin{tabular}{lccccc}
\hline & \multicolumn{2}{c}{ Courses } & Whole & & \\
& $\begin{array}{c}\text { COMM101 } \\
\mathrm{N}=78\end{array}$ & $\begin{array}{c}\text { COMM151 } \\
\text { P=65 }\end{array}$ & $\begin{array}{c}\text { Population } \\
\mathrm{N}=143\end{array}$ & $\mathrm{t}$ & $\mathrm{p}$ \\
\hline Min & 70 & 65 & 65 & & \\
Max & 106 & 108 & 108 & -1.9651 & .0257 \\
Average & 88 & 91 & 89 & & \\
\hline
\end{tabular}

According to Table 1, the students' average scores for the responsibility construct varied between 65 and 108. The average score was 89, which indicates a moderate level. When the scores for the two courses are considered, it is seen that the average scores of COMM151 students are slightly higher than that of the COMM101 students (91 vs. 88). The difference was at a statistically significant level $(\mathrm{p}=.0257<.05)$.

The students' responsibility scores were also compared according to gender. The results can be seen in Table 2 below.

Table 2. Responsibility scores according to gender

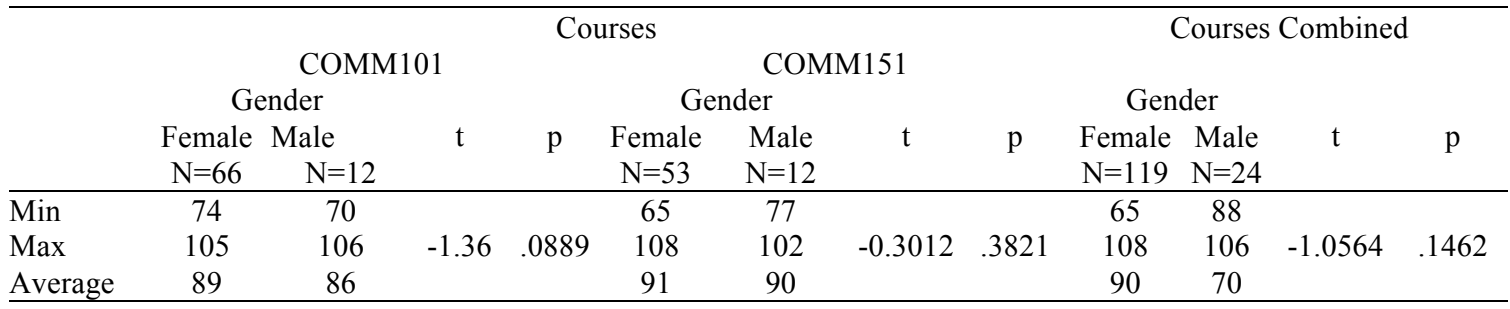

Table 2 shows that the female students' responsibility scores varied between 65 and 108, with a mean score of 90. On the other hand, the male students' scores ranged between 88 and 106, with a mean score of 70 . The difference between these two scores indicates that the female students were more responsibility oriented than the male students. However, t-test conducted to identify the statistical significance of this difference showed that it was not at a statistically significant level $(\mathrm{p}=.1462>.05)$. The students' scores were also compared relative to their gender factor in the two courses. The results revealed that the average scores for both genders were higher in the second course (COMM151) despite a lack of statistically significant differences.

The second research question aimed at identifying the students' interpersonal communication orientations. The results in response to this question can be seen in Table 3.

Table 3. Interpersonal Communication Scores

\begin{tabular}{|c|c|c|c|c|c|}
\hline & \multicolumn{2}{|c|}{ Courses } & \multirow{2}{*}{$\begin{array}{c}\text { Whole } \\
\text { Population } \\
\mathrm{N}=143 \\
\end{array}$} & \multirow[b]{2}{*}{$\mathrm{t}$} & \multirow[b]{2}{*}{$\mathrm{p}$} \\
\hline & $\begin{array}{c}\text { COMM101 } \\
\mathrm{N}=78\end{array}$ & $\begin{array}{c}\text { COMM151 } \\
\mathrm{N}=65\end{array}$ & & & \\
\hline Min & 69 & 68 & 68 & & \\
\hline Max & 120 & 120 & 120 & -1.3592 & .088 \\
\hline Average & 99 & 95 & 97 & & \\
\hline
\end{tabular}


Deveci, T., Ayish, N. (2018). Personal responsibility and interpersonal communication in a project-based learning environment. International Journal of Social Sciences and Education Research, 4(1), 1-17.

Table 3 reveals that the students' interpersonal communication scores varied between 68 and 120. The average score was 97 , which is above the average score (62.5) computed for the scale. Data were also analysed comparing the scores for the two courses. It appeared that the average score for COMM101 was slightly higher than that of COMM151 (99 vs. 95). However, this difference was not at a statistically significant level $(p=.088>.05)$.

The students' interpersonal communication scores were also compared considering the gender factor. The results can be seen in Table 4 .

Table 4. Interpersonal communication scores according to gender

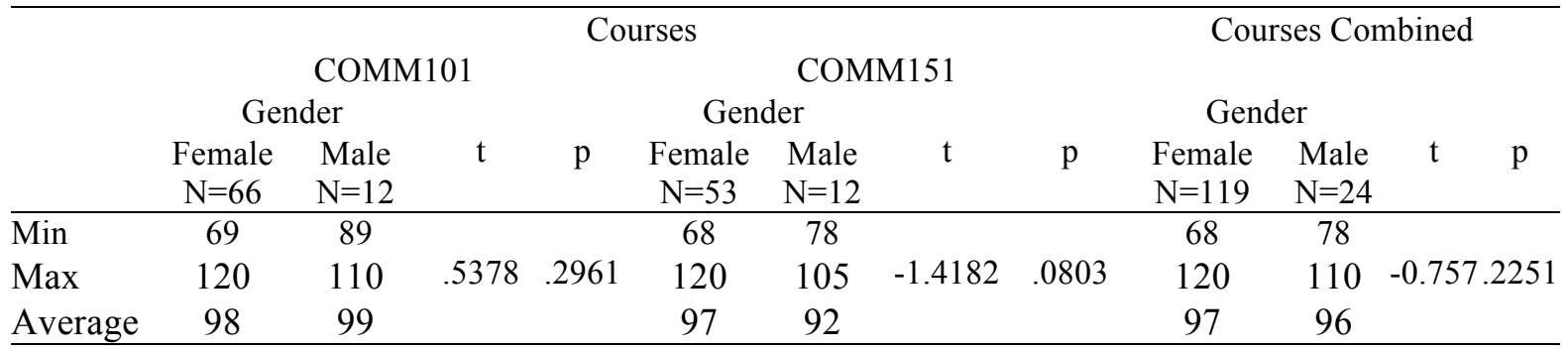

Table 4 shows that the range of female students' scores (68-120) was more varied than those of the male students (78-110). However, their average score was almost the same (97 and 96), and there was not a statistically significant difference between the two data sets. Scores for both genders were also compared in the two courses. It was found that female and male students' average scores in COMM101 was almost the same (99 and 98). On the other hand, their scores in COMM151 differed to the advantage of the female students (97 vs. 92). However, there was no statistically significant differences between the scores according to gender in either of the courses $(\mathrm{p}=.2961>.05 \& \mathrm{p}=.0803>.05)$.

The third research question asked what kind of relationship exists between students' responsibility and interpersonal communication scores, and whether or not it changes according to gender and course. The results of data analysis for this purpose are displayed in Table 5.

Table 5. Pearson product-moment correlations of PR and IC scores

\begin{tabular}{|c|c|c|c|c|}
\hline \multirow{3}{*}{\multicolumn{2}{|c|}{ Whole population $(\mathrm{N}=143)$}} & & Responsibility & Interp. Com. \\
\hline & & Responsibility & 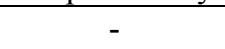 & $.0171^{*} ; .8393^{\mathrm{a}}$ \\
\hline & & Interp. Com. & $.0171^{*}, .8393^{\mathrm{a}}$ & \\
\hline \multirow[t]{8}{*}{ Gender } & Female & Responsibility & - & $.0478^{*}, .6057^{\mathrm{a}}$ \\
\hline & $(\mathrm{N}=119)$ & Interp. Com. & $.0478^{*}, .6057^{\mathrm{a}}$ & - \\
\hline & Male & Responsibility & - & $.0207^{*}, .3318^{\mathrm{a}}$ \\
\hline & $(\mathrm{N}=24)$ & Interp. Com. & $.0207 * ; .3318^{a}$ & - \\
\hline & COMM101 & Responsibility & - & $.1329 * ; .246^{\mathrm{a}}$ \\
\hline & $(\mathrm{N}=78)$ & Interp. Com. & $.1329^{*}, .246^{\mathrm{a}}$ & - \\
\hline & COMM151 & Responsibility & - & $-.003 * ; .981^{\mathrm{a}}$ \\
\hline & $(\mathrm{N}=65)$ & Interp. Com. & $-.003 * ; .981^{\mathrm{a}}$ & - \\
\hline
\end{tabular}

*Values are product-moment correlation coefficient (r);

${ }^{\mathrm{a}} \mathrm{p}<.05$ (2-tailed)

According to Table 5 , the correlation coefficient ( $\mathrm{r}$ ) for the whole population equals .0171 with a p value of .8393 , which indicates a weak positive correlation without a statistically significant level. When gender is considered, a positive correlation was found between the female students' 
Deveci, T., Ayish, N. (2018). Personal responsibility and interpersonal communication in a project-based learning environment. International Journal of Social Sciences and Education Research, 4(1), 1-17.

responsibility and interpersonal communication scores $(\mathrm{r}=.0478)$. However, the correlation was weak, and the correlation was not at a statistically significant level $(p=.6057>.05)$. This was also the case with the male students' scores ( $(\mathrm{r}=.207, \mathrm{p}=.3318)$. In addition, a weak positive correlation was detected between COMM101 students' responsibility and interpersonal communication skills $(\mathrm{r}=.1329)$, but the level of correlation lacked statistical significance $(\mathrm{p}=.246>.05)$. On the other hand, a weak negative correlation was detected between COMM151 students' responsibility and interpersonal communication skills. However, the result was not statistically significant $(\mathrm{p}=.981)$.

\section{Discussion}

Understanding the role personal responsibility and interpersonal communication play in promoting learning and student success is a growing area of interest among many educators. The current study considered three questions related to these two concepts. The results for the first research question exploring students' responsibility levels indicate that, overall, students scored above average (89). COMM151 students, in particular, scored, on average, slightly higher than COMM101 students at a statistically significant level. Considering the comparatively longer length of time these students had in a team-based learning environment (TBL), this difference is not surprising. However, it is somewhat surprising that COMM101 students also scored above the average despite the relatively shorter exposure they had to TBL. This is still important to note considering the observation that many students in the Gulf region have had little opportunity to practice PBL or teaming (Bielenberg \& Gillway, 2007; Saterbak, Volz \& Wettergreen, 2016). Our data then indicate that even relatively brief involvement with TBL can result in positive outcomes in terms of responsible behaviours. This suggests that if students in high school, for example, are exposed to the principles of PBL and teaming in a meaningful way before entering university, they should benefit from more intense PBL and teaming that typically occurs at the tertiary level. These findings support the notion that PBL has the potential to help students recognize their abilities as well as those of their peers (Sweet, 2008), resulting in more responsibility assumed for learning (Schmidt, Loyens, Van Gog, \& Paas, 2006). Indeed, there is evidence that PBL can lead to greater teaming experiences, which, in turn, should contribute to a student's personal responsibility.

The results also showed that responsibility levels change according to gender, but not at statistically significant levels. While female students are more responsibility oriented than male students, the fact that no statistical significance exists between the two genders suggests that gender does not impact responsibility levels significantly. This is an important finding, because it offers insight into the way females and males perceive personal responsibility and how such perceptions potentially impact students and teaming. Based on our experience, we assumed that female students were more responsible than male students. This is also what Cesur and Ertas (2013) found among Turkish preparatory class students. However, our findings indicate that this is not necessarily the case. This has implications for pedagogy, the way courses are designed, classroom practice, the level and structure of teaming that is incorporated into a course, and the expectations instructors have of their students.

The students' scores were also compared relative to their gender factor in the two courses. Results reveal that the average scores for both genders were higher in COMM151 despite a lack of statistically significant differences. As we discussed above, this is likely due to the extra time students have had to develop their teaming experience through PBL. 
Deveci, T., Ayish, N. (2018). Personal responsibility and interpersonal communication in a project-based learning environment. International Journal of Social Sciences and Education Research, 4(1), 1-17.

The results for the second question, which aimed to identify the students' interpersonal communication orientations, indicate that the average score for students was significantly above the scale's average score. This may be due to the collectivist nature of Emirati culture. Unlike more individualistic cultures (e.g., the US), it has been shown that individuals from collectivistic cultures tend to spend more time communicating with others in small and large groups, all of which likely contributes to stronger interpersonal communication skills (Darwish \& Huber, 2003; Findlow, 2006; Palfreyman, 2014). In addition, while this is the first time for many students entering COMM101 to work extensively on teams or in a PBL environment, ample evidence indicates that such experience leads to increased interpersonal competencies (Schmidt, Loyens, Van Gog, \& Paas, 2006). Worth noting is the finding that the average score for COMM101 students was slightly higher than that of COMM151 students. Although this difference was not statistically significant, it is surprising that students with less exposure to PBL and teaming scored higher than peers in the second semester course. One reason for this likely stems from the nature of COMM151. While teaming is a central part of the course, just like it is in COMM101, a greater emphasis is placed on individual responsibility and accountability through several short assignments not found in COMM101. In addition, some students may have had a negative team experience in COMM101, and this may have impacted their willingness to interact and engage with peers in COMM151. This is likely the case for those students that feel that they did more work than other team members, yet all on the team receive the same grade.

In terms of gender and the levels of interpersonal communication, no statistically significant difference exists. The same is true for any changes due to the course. This may indicate, similar to the findings noted above for gender and course differences relative to personal responsibility levels, that males and females have more in common in terms of interpersonal communication than is generally assumed to be the case (Caspi, Chajut \& Saporta, 2008; Alavinia \& Alikhani, 2014).

The third research question sought to better understand the kind of relationship that exists between a student's responsibility and interpersonal communication scores. While there is a weak positive correlation over all, there is no statistical significance. Although we had expected that this relationship would be positive and statistically significant based on our experience, the relatively positive relationship is still important to note. This is because it offers at least some indication that students who actively take responsibility for their learning as well as the learning of others are likely to improve their interpersonal communication skills. It is not surprising that students that feel valued by their teammates develop positive relationships with them. After all, the mutual respect created by this experience enhances the rapport in the team by establishing closer contact and cooperation (Aswathappa \& Dash, 2008; Dauletova, 2014). This finding is also important because it offers insight into the role both constructs play in promoting student success.

Part of this question also attempted to uncover if this relationship changes according to gender and course. A positive correlation was found between both the female and the male students' responsibility and interpersonal communication scores. Although the correlation was weak and not statistically significant, this finding suggests that both genders likely benefit from developing their responsibility skills in order to enjoy enhanced relationships with their peers. Similar results were found when COMM101 students' scores were considered.

Interestingly, a weak negative correlation was detected between COMM151 students' responsibility and interpersonal communication skills, but the results were not statistically significant. 
Deveci, T., Ayish, N. (2018). Personal responsibility and interpersonal communication in a project-based learning environment. International Journal of Social Sciences and Education Research, 4(1), 1-17.

This negative correlation is still particularly important to note considering the literature on the concepts. We believe one reason for this surprising result may be due to certain students' experiences in their teams. COMM151 requires individual students to take comparatively greater responsibility for their learning outside of class in order to contribute to their team assignments. Some team members who try to contribute to a team assignment, but encounter a team member who does not contribute, for example, may have developed a negative attitude toward team work, decreasing their willingness to develop stronger relationships with their peers. Three team member behaviors, in particular, have been cited as the most problematic in this regard: slacking, social-loafing, and free-riding (Brooks \& Ammons, 2003; Jassawalla, Malshe, \& Sashittal, 2008; Pieterse \& Thompson, 2010). These behaviours tend to be exacerbated among freshman students because of their limited teaming experience. Such students have had little practice in teaming, often lack fundamental skills in being able to effectively contribute to team development, and may not fully appreciate their role as essential members of a larger whole (Bacon, Stewart, \& Silver, 1999; Oakley, Hanna, Kuzmyn, \& Felder, 2007).

\section{Recommendations}

The results of this study suggest that team-based learning experiences in a PBL environment encourage students to take active responsibility for their own as well as their peers' learning. This in turn positively affects their interpersonal communication. However, freshman students' relatively limited exposure with team-based learning prior to college likely limits their ability to benefit fully from such experiential learning experiences. In order to ameliorate this issue, PBL can be introduced to K-12 curricula within the region, which still appears to be heavily based on rotelearning. This should serve as a strong foundation upon which more growth and development can be built during students' freshman studies.

Considering the finding related to the role of gender in responsibility, we suggest that female students' comparatively stronger orientation towards responsible behaviours be matched with male students' slightly less strong orientations towards assuming responsibility for learning. To this end, instructors need to identify the factors that contribute to the two genders' expectations of responsible behaviours in the learning context. Students' learning aspirations may be a factor; therefore, raising students' awareness of the opposite sex's learning aspirations would yield to some overlapping, which in turn would generate responsible learning behaviours in both genders. This would help students work more effectively in teams made up of both genders. However, male and female students should not be forced to work in mixed-gender teams unless they are willing. This is particularly important in an educational context like ours where students are currently attended segregated classes on segregated campuses. Even in co-educational contexts in the UAE, it appears that many students, when given an opportunity, self-segregate within the same classroom. The physical proximity between genders in such classrooms, however, should still allow students to observe similarities and differences between different responsible behaviours. Having been introduced to such learning environments during their freshman studies, both male and female students would be expected to work more effectively in subsequent years at and beyond university.

On the other hand, the findings related to students' interpersonal communication aptitude indicate their readiness and willingness for learning activities that could further engage them through social interaction. Partly influenced by their collectivist culture, these students may be 
Deveci, T., Ayish, N. (2018). Personal responsibility and interpersonal communication in a project-based learning environment. International Journal of Social Sciences and Education Research, 4(1), 1-17.

expected to devote themselves to the well-being of their peers if a sense of community and belongingness is created in their teams. To this end, it would be useful for instructors to encourage team members to get to know each other on a personal level. Team building activities can be employed, such as having teams create a team charter where team members map out norms and share meaningful information about themselves, including aptitudes, learning styles, expectations, and personal needs to ensure a successful teaming experience.

Considering the possible reasons for COMM151 students' relatively lower interpersonal communication aptitude discussed above, it is recommended that teams should provide regular feedback to the instructor and to team members. This would allow instructors to identify any emerging issues early on and devise ways to effectively address them. A session on conflict resolution, for example, could be incorporated into the curriculum along with a lesson on the importance of developing one's emotional intelligence as a way to avoid conflict and build better relationships.

Finally, because this research was limited to students' responsibility and interpersonal communication traits within the domains of two PBL courses, we recommend that researchers investigate how students use these skills in non-PBL courses. The similarities and differences identified between different types of courses could elucidate student attributes more fully. Also, given that this was a quantitative study, conducting a qualitative study by expanding on this initial research would add important information about a rather complex area. Researchers could, for example, identify the factors that impact students' responsibility and interpersonal communication skills. This would help instruction develop to better support content and learning activities that are more compatible with such skills. Investigating students' use of responsibility and interpersonal communication in relation to their academic success and overall well-being at university would also be of interest to many educators.

\section{Conclusion}

This study reveals that PBL can enhance personal responsibility and interpersonal communication in meaningful ways. While female students are slightly more responsibility oriented than male students, both groups benefit by working on team-based projects that help promote personal responsibility and the development of interpersonal skills through various interactions and assignments. Worth noting is that second-semester students taking COMM151 had higher responsibility orientations than first-semester students taking COMM101. This suggests that students benefit from more experience with PBL and that promoting PBL in elementary and secondary school should provide students with a solid foundation upon which to build their personal responsibility and interpersonal skills in university.

It is also worth noting that the average score for students' interpersonal communication orientations were significantly above the scale's average score. One reason for this difference might stem from the context in which this study was conducted. Given the collectivist nature of Emirati culture, students have likely benefited from spending significant amounts of time interacting with others, which, in turn, has strengthened their interpersonal communication skills. Better understanding the cultural background of our students may offer insight into how best to help them more effectively develop their interpersonal communication skills.

Finally, our study revealed a weak, but not statistically significant negative correlation between COMM151 students' responsibility and interpersonal communication skills. Although this 
Deveci, T., Ayish, N. (2018). Personal responsibility and interpersonal communication in a project-based learning environment. International Journal of Social Sciences and Education Research, 4(1), 1-17.

finding was unexpected, it highlights the need to pay attention to the teaming experiences of students in a PBL environment. In particular, better understanding and monitoring team dynamics and the interactions of team members, especially behaviours associated with slacking, socialloafing, and free-riding, can help foster stronger relationships with peers and ameliorate some of the negative impact on students' attitude toward team work.

\section{References}

ABET (2013, January 7). Criteria for accrediting engineering programs. Baltimore, MD: Engineering Accreditation Commission. Retrieved from http://www.abet.org/ uploadedFiles/ Accreditation/Accreditation_Process/Accreditation_Documents/Current/eac-criteria-2012-2013.pdf

Adamson, J., \& Sert, N. (2012). Autonomy in learning English as a foreign language. International Journal of Global Education, 1(2), 23-27.

Alavinia, P., \& Alikhani, M. A. (2014). Willingness to communicate reappraised in the light of emotional intelligence and gender differences. Procedia - Social and Behavioral Sciences, 98, 143-152.

Alves, A. C., Mesquita, D., Moreira, F., \& Fernandes, S. (2012). Teamwork in project-based learning: Engineering students' perceptions of strengths and weakness. Proceedings of the Fourth International Symposium on Project Approaches in Engineering Education (PAEE'2012), 23-32.

Amelink, C. T., \& Creamer, E. G. (2010). Gender differences in elements of the undergraduate experience that influence satisfaction with the engineering major and the intent to pursue engineering as a career. Journal Of Engineering Education, 99(1), 81-92.

Arnett, R. C., Fritz, J. M. H., \& Bell, L. M. (2009). Communication, ethics, literacy: Dialogue and difference. London: Sage.

Aswathappa, K., \& Dash, S. (2008). International human resource management. New Delhi: Tata McGraw-Hill Publishing Company Limited.

Atkinson, J. (2001). Developing teams through project-based learning. Hamphsire: Gower Publishing Limited.

Bielenberg, B., \& Gillway, M. (2007). Adapting problem-based learning to meet the life-long learning needs of developmental students. Learning and Teaching in Higher Education: Gulf Perspectives, 4(1).

Boss, S., \& Krauss, J. (2014). Reinventing project-based learning: Your field guide to real-world projects in the digital age ( $2^{\text {nd }}$ Edition.). Eugene, OR: International Society for Technology in Education.

Bacon, D. R., Stewart, K. A., \& Silver W. S. (1999). Lessons from the best and worst student team experiences: How a teacher can make a difference. Journal of Management Education, 23(5), 467-488.

Brooks, C. M., \& Ammons, J. L. (2003). Free Riding in Group Projects and the Effects of Timing, Frequency, and Specificity of Criteria in Peer Assessments. Journal of Education for Business, 78(5), 268272.

Buck Instite for Eduaction (n.d.). What is project-based learning (PBL)? Retrieved from http://bie.org/about/what_pbl

Caspi, A., Chajut, E., \& Saporta, K. (2008). Participation in class and in online discussions: Gender differences. Computers \& Education, 50(3), 718-724.

Cesur, K., \& Ertas, A. (2013). Who is more responsible? Preparatory class students' perceptions of responsibility. International Association of Research in Foreign Language Education and Applied Linguistics ELT Research Journal, 2(2), 70-81. 
Deveci, T., Ayish, N. (2018). Personal responsibility and interpersonal communication in a project-based learning environment. International Journal of Social Sciences and Education Research, 4(1), 1-17.

Chartier, B. J., \& Gibson, B. A. (2007). Project-based learning: A search and rescue UAV: Perceptions of an undergraduate engineering design team: A preliminary study. Proceedings of the 18th conference of the Australasian Association for Engineering Education, 1-6.

Dana, S. W. (2007). Implementing team-based learning in an introduction to law course. Journal of Legal Studies Education, 24, 59-108.

Dauletova, V. (2014). Expanding Omani learners' horizons through project-based learning: A case study. Business and Professional Communication Quarterly, 77(2), 183-203.

Darwish, A. F. E., \& Huber, G. L. (2003). Individualism vs. collectivism in different cultures: A crosscultural study. Intercultural Education, 14(1), 47-55.

Edgar, S. (2015). Identifying the influence of gender on motivation and engagement levels in student physiotherapists. Medical Teacher, 37(4), 348-353.

Findlow, S. (2006). Higher education and linguistic dualism in the Arab Gulf. British Journal of Sociology of Education, 27(1), 19-36.

Fines, B. G. (2012). Using team based learning in the professional responsibility course. Retrieved from http://law2.umkc.edu/faculty/profiles/glesnerfines/Using\%20Team\%20Based\%20Learning\%20in\%20

Fink, L. D. (2002). Beyond small groups: Harnessing the extraordinary power of learning teams. In L. K. Michaelsen, A. B. Knight \& L. D. Fink (Eds.). Team-based learning: A transformative use of small groups (pp. 3-26). Wesport, CT: Praeger Publishers.

Gray, J. (1992). Men are from Mars, women are from Venus: A practical guide for improving communication and getting what you want in your relationships. New York, NY: Harper Collins

Hills, H. (2001). Team-based learning. Hampshire: Gower Publishing Limited.

Ingram, S., \& Parker, A. (2002). The influence of gender on collaborative projects in an engineering classroom. IEEE Transactions on Professional Communication, 45(1), 7-20.

Iwamoto, D. H., Hargis, J., \& Vuong, K. (2016). The effect of project-based learning on student performance: An action research study. International Journal for the scholarship of Technology Enhanced Learning, 1(1)-24-42.

Jassawalla, A. J., Malshe, A. A., \& Sashittal, H. S. (2008). Student perceptions of social loafing in undergraduate business classroom teams. Decision Sciences Journal of Innovative Education, 6(2), 403-426.

Jones, B., Ruff, C., \& Paretti, M. (2013). The impact of engineering identification and stereotypes on undergraduate women's achievement and persistence in engineering. Social Psychology of Education, $16(3), 471-493$.

Kannan, R. R., Mahajan, S. \& Rajkumar, R. (2016). An approach on effective \& efficient project-based learning (PBL). International Journal of Applied Engineering Research, 11(8), 5920-5926.

Kobalgrum, D. D., \& Grum, B. B. (2015). Competitiveness and motivation for education among university students. International Journal on New Trends in Education \& Their Implications, 6(3), 125-136.

Konrath, S. H., O’Brien, E. H., \& Hsing, C. (2011). Changes in dispositional empathy in American college students over time: A meta-analysis. Personality and Social Psychology Review, 15(2), 180-198.

Korkut, F. (1996). İletişim becerilerini değerlendirme ölçeğinin geliştirilmesi: Güvenirlik ve geçerlik çalışmaları. Psikolojik Danışma ve Rehberlik Dergisi, 2(7): 18-23.

Lane, S. D. (2016). Interpersonal communication: Competence and contexts ( $2^{\text {nd }}$ Edition). London and New York: Routledge. 
Deveci, T., Ayish, N. (2018). Personal responsibility and interpersonal communication in a project-based learning environment. International Journal of Social Sciences and Education Research, 4(1), 1-17.

Larmer, J., Mergendoller, J., \& Boss, S. (2015). Setting the standard for project based learning. Alexandria, VA: Association for Supervision and Curriculum Development.

LaVoi, N. M. (2007). Interpersonal communicaiton and conflict in the coach-athlete relationship. In S. Jowett \& D. Lavallee (Eds.) Social psychology in sport (pp. 28-40). Champaign, IL: Human Kinetics.

Linley, A. P., \& Maltby, J. (2009). Personal responsibility. In S. J. Lopez(Ed.). The encyclopedia of positive psychology (p. 685). West Sussex: Blackwell Publishing Ltd.

Littlewood, W. (1999). DeMining and developing autonomy in East Asian contexts. Applied Linguistics, 20(1), 71-94.

Mergler, A. (2007). Personal responsibility. The creation, implementation and evaluation of a school-based program. (Unpublished doctoral dissertation). Queensland University of Technology, Brisbane.

Michaelsen, L. K., \& Sweet, M. (2008). The essential elements of team-based learning. In L. K. Michaelsen, M. Sweet \& D. X. Parmelee (Eds). New directions for teaching and learning (pp. 7-27). San Francisco, CA: Jossey-Bass.

Musa, F., Mufti, N, Latiff, R. A., \& Amin, M. M. (2012). Project-based learning (PjBL): Including soft skills in $21^{\text {st }}$ century workplace. Procedia- Social and Behavioral Sciences, 59, 565-573.

Oakley, B.A. Hanna, D.M., Kuzmyn, Z., \& Felder, R. M. (2007). Best practices involving teamwork in the classroom: Results from a survey of 6435 engineering student respondents. IEEE Transactions on Education, 50, 266-272.

Ozel, S. (2013). $W^{3}$ of project-based learning: Who, where, and when: Revisited. In R. M. Capraro, M. M. Capraro \& J. Margon (Eds.), STEM Project-based learning: An integrated science, technology, engineering (pp. 41-49). Rotterdam: Sense Publishers.

Palfreyman, D. (2014). Introduction: cultural aspects of learning and teaching. Learning and Teaching in Higher Education: Gulf Perspectives, 11(2).

Pennycook, A. (1997). Cultural alternatives and autonomy, In P. Benson \& P. Voller (Eds.) Autonomy and Independence in Language Learning. (pp. 35-53) Harlow: Longman.

Pfeiffer, J. W. (1998). Conditions that hinder effective communication. San Fransicao: Jossey-Bass/Pfeiffer.

Pieterse, V., \& Thompson, L. (2010). Academic alignment to reduce the presence of 'social loafers' and 'diligent isolates' in student teams. Teaching in Higher Education, 15(4), 355-367.

Saterbak, A., Volz, T., \& Wettergreen, M. (2016). Implementing and Assessing a Flipped Classroom Model for First-Year Engineering Design. Advances in Engineering Education, 5(3), 1-29.

Samad, A. A., Rashid, J. M., Rahman, S. Z. S. A., \& Hussein, H. (2014). Investigating the implementation of team-based learning in a university level teacher education course. International Journal of Asian Social Science, 4(2) 249-257.

Severiens, S., \& Dam, G. (2012). Leaving college: A gender comparison in male and female-dominated programs. Research in Higher Education, 53(4), 453-470.

Schmidt, H. G., Loyens, S. M., Van Gog, T., \& Paas, F. (2006). Problem-based learning is compatible with human cognitive architecture: Commentary on Kirschner, Sweller, and Clark. Educational Psychologist, 42(2), 91-97.

Sweet, M. C. (2008). Individual and peer calibration in team-based testing (Unpublished doctoral dissertation). The University of Texas at Austin, Texas.

Tannen, D. (2007). You just don't understand: Women and men in conversation. New York, NY: William Morrow. 
Deveci, T., Ayish, N. (2018). Personal responsibility and interpersonal communication in a project-based learning environment. International Journal of Social Sciences and Education Research, 4(1), 1-17.

Thabet, R. (2008). Do public schools in UAE foster critical thinking as one of the main objectives of education? (Unpublished master's thesis,) British University in Dubai, Dubai.

Uche, U. (2012). Is it normal for teenagers to lack empathy?. Psychology Today. Retrieved from https://www.psychologytoday.com/blog/promoting-empathy-your-teen/201209/is-it-normal-teenagers-lack-empathy

Üstünlüoğlu, E. (2009). Autonomy in language learning: Do students take responsibility for their learning?. Journal of Theory \& Practice in Education, 5(2), 148-169.

West, R., \& Turner, L. H. (2009). Understanding interpersonal communication. Boston: Wadsworth CENGAGE Learning.

Wolfe, J., \& Powell, E. (2009). Biases in interpersonal communication: How engineering students perceive gender typical speech acts in teamwork. Journal of Engineering Education, 98(1), 5-16.

Wood, J. T. (2016). Interpersonal communication: Everyday encounters. Eight Edition. Balmont, CA: Thomson Wadsworth.

Vygotsky, L.S. (1962). Thought and language. Cambridge, MA: MIT Press. 